\title{
Diagnostic features of tuberous sclerosis complex: case report and literature review
}

\author{
Sultan Abdulwadoud Alshoabi ${ }^{1} \wedge$, Abdullgabbar M. Hamid ${ }^{2}$, Fahad H. Alhazmi ${ }^{1}$, Abdulaziz A. Qurashi ${ }^{1}$, \\ Osamah M. Abdulaal ${ }^{1}$, Khaled M. Aloufi ${ }^{1}$, Tareef S. Daqqaq ${ }^{3}$ \\ ${ }^{1}$ Department of Diagnostic Radiology Technology, College of Applied Medical Sciences, Taibah University, Almadinah Almunawwarah, Kingdom \\ of Saudi Arabia; ${ }^{2}$ Radiology Department, Rush University Medical Center, Chicago, IL, USA; ${ }^{3}$ Radiology Department, Faculty of Medicine, Taibah \\ University, Almadinah Almunawwarah, Kingdom of Saudi Arabia
}

Correspondence to: Sultan Abdulwadoud Alshoabi. Associate Professor of Radiology, Department of Diagnostic Radiology Technology, College of Applied Medical Sciences, Taibah University, Almadinah Almunawwarah, Kingdom of Saudi Arabia. Email: alshoabisultan@yahoo.com.

\begin{abstract}
Tuberous sclerosis complex (TSC) is a rare autosomal dominant genetic syndrome that is caused by mutations in the tumour suppressor genes TSC1 or TSC2 which causes multiorgan growths. TSC presents at any age as a wide range of clinical and phenotypic manifestations with varying severity. The main goal of this article was to state two cases of TSC and review the most commonly reported major and minor diagnostic clinical features and the most common features that led to an investigation of possible TSC diagnosis. Herein, we report two cases of TSC, which both presented with seizures during the first 6 months of life. Case 1 presented with multiple types of seizures from 6 months of age and was diagnosed by multiple calcified subependymal nodules (SENs) detected by computed tomography and magnetic resonance imaging (MRI). Case 2 presented with seizures from 3 months of age and was diagnosed prenatally when a tumour was seen in her heart during antenatal ultrasonography. In conclusion, the literature review revealed that neurological manifestations (mainly seizures) were the main feature that led to investigation and diagnosis of TSC followed by abdominal manifestations (mainly renal features) and antenatal follow-up imaging. Other manifestations in skin, chest, eyes, teeth and heart rarely led to TSC diagnosis. In some cases, TSC was incidentally discovered by medical imaging. The cortical tubers, SENs, and subependymal giant cell astrocytomas brain lesions were the most commonly reported major features. Skin features including angiofibromas, ungual fibromas and shagreen patch were the second most common major features reported in the literature. However, skin manifestations were not a common led to investigation and diagnosis of TSC. Renal features, mainly angiomyolipomas (AMLs), were the third most common major feature reported. Medical imaging plays an essential role in diagnosis of TSC, and clinical features are important clues that lead to investigation for the disease.
\end{abstract}

Keywords: Tuberous sclerosis complex (TSC); clinical diagnostic criteria; major features; minor features; subependymal nodules (SENs); renal angiomyolipomas (AMLs); cardiac rhabdomyomas

Submitted Apr 17, 2021. Accepted for publication Jul 06, 2021.

doi: $10.21037 /$ qims-21-412

View this article at: https://dx.doi.org/10.21037/qims-21-412

^ ORCID: Sultan Abdulwadoud Alshoabi, 0000-0001-5049-6989; Fahad H. Alhazmi, 0000-0002-8196-3233. 


\section{Introduction}

Tuberous sclerosis complex (TSC) is a rare autosomal dominant multisystem syndrome characterised by formation of hamartomas in multiple organs of the body including the skin, brain, kidneys, lungs, and heart. It presents as a wide variety of phenotypic manifestations of varying severity. TSC is caused by mutations in the tumour suppressor genes TSC-1 (TSC1), which encodes hamartin protein $(130-\mathrm{kDa})$ on the long arm of chromosome $9(9 \mathrm{q} 34)$ or TSC-2 (TSC2), which encodes tuberin protein $(200-\mathrm{kDa})$ on the short arm of chromosome 16 (16p13) (1-3). TSC affects the central nervous system in the majority of patients causing a wide range of structural abnormalities such as cortical tubers, and subependymal nodules (SENs) and functional manifestations such as seizures, intellectual disability and behavioural changes. It classically presents in childhood with the Vogt triad of seizures, adenoma sebaceum (facial angiofibromas), and intellectual disorders. Seizure, and facial angiofibromas present in three quarters of patients and intellectual disorders presents in half of patients; the full triad is only seen in a minority of patients. Therefore, diagnostic criteria have been established to aid the diagnosis of TSC $(1,2,4)$. The second "International Tuberous Sclerosis Complex Consensus Conference" held in Washington, DC, in 2012 revised the clinical diagnostic criteria for TSC and classified them as major and minor features (Figure 1). The most significant change was the incorporation of TSC1 and TSC2 molecular testing into diagnostic criteria. The diagnosis of definitive TSC requires at least two major features or one major and at least two minor features (Figure 1). Genetic diagnostic criteria include identification of a pathogenic mutation in TSC1 or TSC2 in normal tissue which is sufficient to diagnose TSC $(4,5)$.

Diagnosis of TSC by medical imaging includes detection of any of the following manifestations: (I) renal angiomyolipomas (AMLs), hepatic AMLs, splenic hamartomas, and renal cysts; (II) intracranial SENs, cortical tubers, and subependymal giant cell astrocytoma (SEGA); (III) lung lymphangioleiomyomatosis (LAM), (IV) cardiac rhabdomyomas; (V) bone lesions. These manifestations occur at different ages. For instance, cortical tubers and cardiac rhabdomyomas may occur in the antenatal period; SENs, and SEGAs may occur in childhood to adolescence; and renal AMLs may occur from childhood to adulthood $(5,6)$. Medical imaging modalities such as multidetector computed tomography (MDCT), magnetic resonance imaging (MRI), and ultrasonography are highly valuable methods for confirming diagnosis of TSC, determining its extent, monitoring progression of disease, and early screening. The surveillance guidelines were recommended by the consensus conference in 2012 including: (I) brain and abdominal MRI every $1-3$ years until 25 years old age in symptom-free TSC patients, and more frequently in patients with SEGA or AMLs with progressive growth; (II) echocardiography every 1-3 years for paediatric TSC patients to monitor cardiac rhabdomyomas; (III) chest MDCT every 5-10 years for women with risk of LAM; (IV) annual detailed dermatologic, ophthalmologic and pulmonary function testing examinations $(6,7)$.

The main goal of this article was to state two cases of TSC and review the most commonly reported major and minor diagnostic clinical features and the most common features that led to an investigation of TSC diagnosis. The novelty of this review lies in the focus on features that led clinicians to suspect that patients had TSC and make a diagnosis of the disease. The literature review included case reports published from January 2016 to June 2020 in journals indexed in PubMed. Case reports were located by conducting a PubMed search with the term "tuberous sclerosis complex case reports". Suitable articles included case reports published in English that reported full information about all systems of the body. Original articles, review articles and case reports that focused only on specific points or that were available in other languages were excluded.

\section{Case presentation}

All procedures performed in studies involving human participants were in accordance with the ethical standards of the institutional and/or national research committee(s) and with the Helsinki Declaration (as revised in 2013). Written informed consent was obtained from the patient or legal guardian.

\section{Case 1}

A 19-year-old male presented to Rush university medical center with recurrent intractable seizures. The patient had had 3-7 attacks per day of multiple types of seizures from 6 month of age. Each attack lasts for seconds to 3 minutes. His seizures had been very difficult to control and he had tried many medications. In addition, the patient had developmental delay and was diagnosed as tuberous sclerosis and intractable seizure disorder (Lennox-Gastaut syndrome). Since the age of 1-year-old, he has had a vagus nerve stimulator (VNS), which had its battery changed 

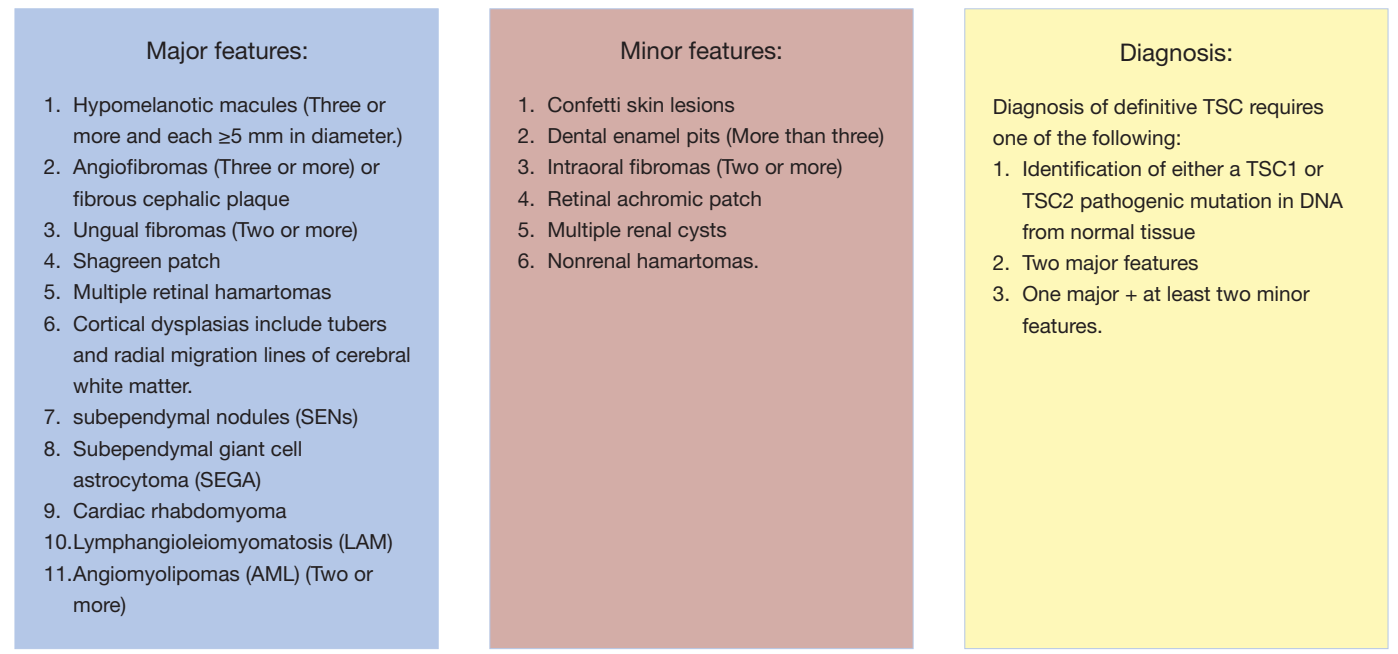

Figure 1 Major and minor features for TSC diagnosis according to the revised clinical diagnostic criteria in the second "International Tuberous Sclerosis Complex Consensus Conference" held in Washington, DC, in 2012. TSC-1, tuberous sclerosis complex-1, TSC-2, tuberous sclerosis complex-2.
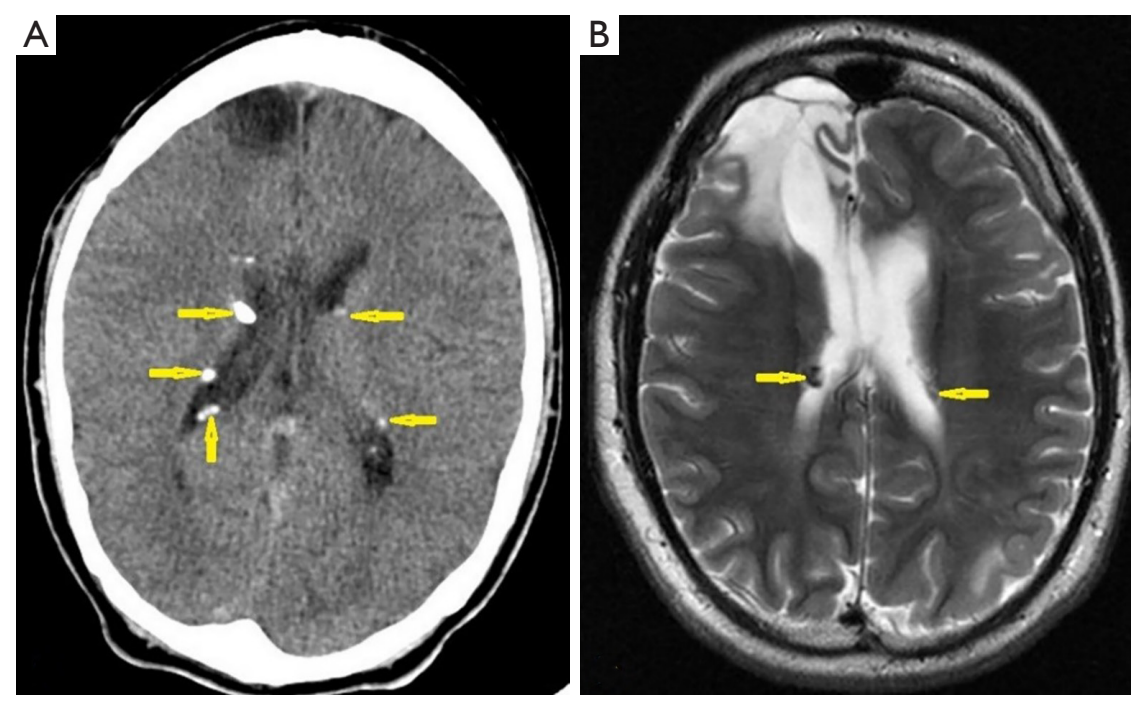

Figure 2 A 19-year-old male known tuberous sclerosis complex (Case 1) showing multiple brain lesions. (A) Axial computed tomography image of the brain showing multiple calcified subependymal nodules (SENs; arrows). (B) Axial T2 weighted-image of magnetic resonance imaging of the brain showing low signal intensity SENs (indicated by arrows) in the same patient. Multiple subcortical white matter tubers were also present (not shown here). Encephalomalacia in the right frontal lobe is post-surgery.

when he was 9 years old. At the age of 2 years, and he underwent right craniotomy and corpus callosotomy with biopsy of ventricular lesion. After surgery, the frequency of generalised convulsions improved, but he continues to have 1-4 tonic seizures during his sleep every night, one generalised tonic clonic seizure (GTCSz) a month and daily atypical absence seizures. Seizures have decreased in frequency over time.

On examination, the patient had facial angiofibromas (Figure 1; feature 2) on his nose and nasolabial folds, a shagreen patch (Figure 1; feature 4) in occipital region and folliculitis on the thigh.

Brain CT showed multiple calcified SENs (Figure 1, feature 7; Figure 2A). The brain T2 weighted-image 

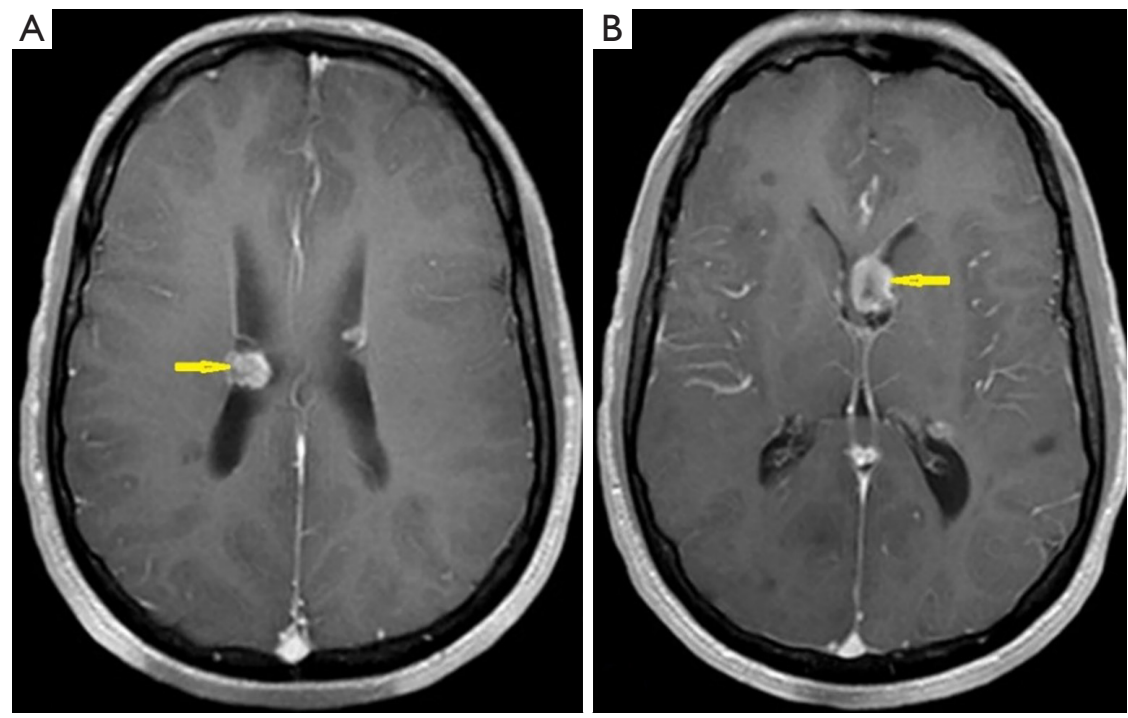

Figure 3 A 19-year-old male known tuberous sclerosis complex (Case 1) with multiple brain lesions. (A) Axial post-contrast T1-weighted images (WIs) magnetic resonance imaging (MRI) of the brain showing gadolinium-enhanced subependymal lesion more than $1 \mathrm{~cm}$ suggesting a subependymal giant cell astrocytoma (SEGA) (arrow). (B) Axial post-contrast T1WIs MRI of the brain showing left enhanced lesion more than $1 \mathrm{~cm}$ in size near the location of foramen of Monro representing biopsy proven SEGA (arrow) in the same patient.
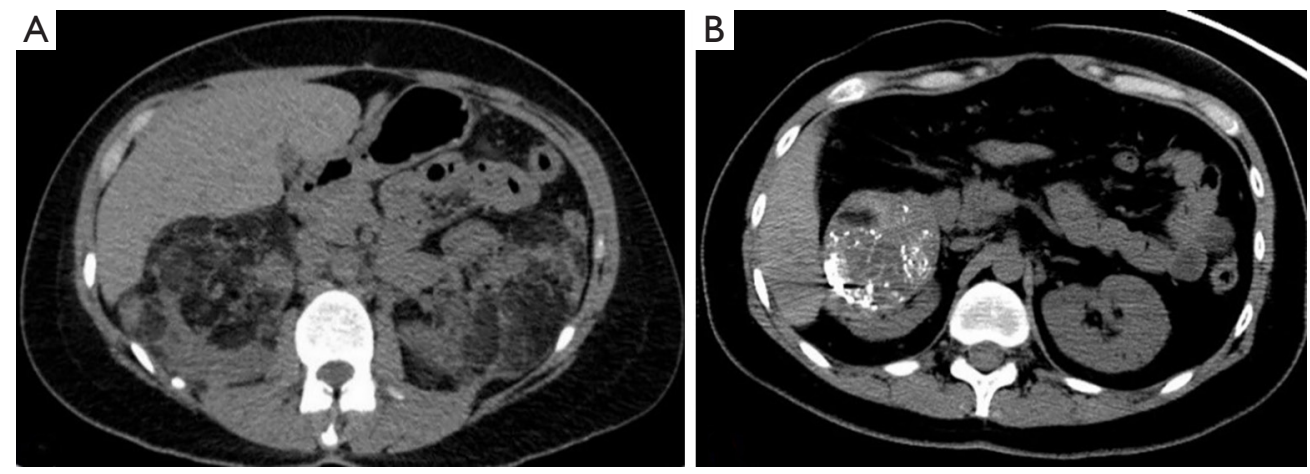

Figure 4 A 19-year-old male known tuberous sclerosis complex (Case 1) with multiple renal lesions. (A) Axial non-enhanced computed tomography (NECT) of the abdomen showing multiple renal masses containing fat consistent with angiomyolipomas (AMLs) in both kidneys. (B) Axial NECT of the abdomen showing post embolization changes on renal AML previously complicated with haemorrhage in the right kidney.

(T2WIs) MRI showed low signal intensity SENs (Figure 2B). Post-contrast T1-weighted images (T1WIs) MRI of the brain showed gadolinium-enhanced subependymal lesions (Figure $3 A$ ) and post-contrast T1WIs MRI of the brain showed enhanced lesion on the left side in the location of foramen of Monro representing a SEGA (Figure 1, feature 8; Figure 3B). Abdominal CT showed multiple AMLs (Figure 1, feature 11) in both kidneys (Figure $4 A$ ) with a large mass in the right kidney (Figure $4 B$ ) which represents biopsy proven AML with previous embolization after haemorrhage. Based on these clinical features and radiology findings, this case was diagnosed as TSC.

\section{Case 2}

A 2.5-year-old female who had experienced seizures from 3 months of age presented to Rush university medical center with increasing seizure frequency and severity. TSC was diagnosed prenatally when a tumour was seen in her heart during antenatal ultrasonography. She was born at 40 weeks' 

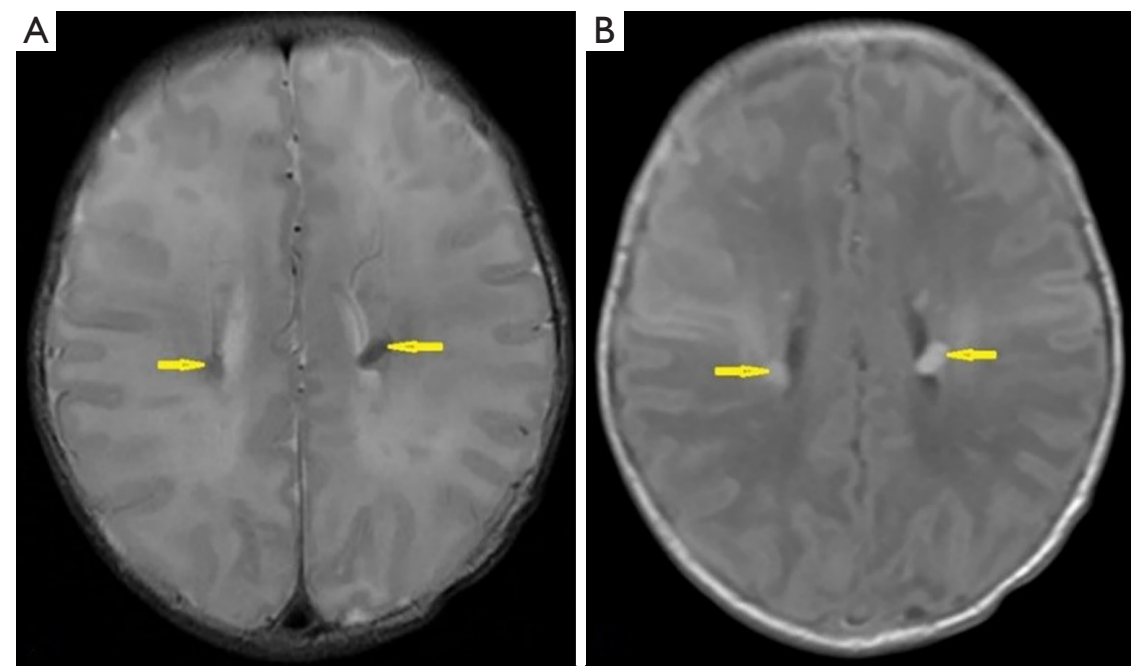

Figure 5 A 2.5-year-old female known tuberous sclerosis complex (Case 2) with multiple brain lesions. (A) Axial T1-weighted images magnetic resonance imaging (MRI) of the brain showing multiple low signal intensity subependymal nodules (SENs; arrows). (B) Axial fluid attenuation inversion recovery (FLAIR) weighted-images MRI of the brain showing the SENs appear of high signal intensity (arrows).
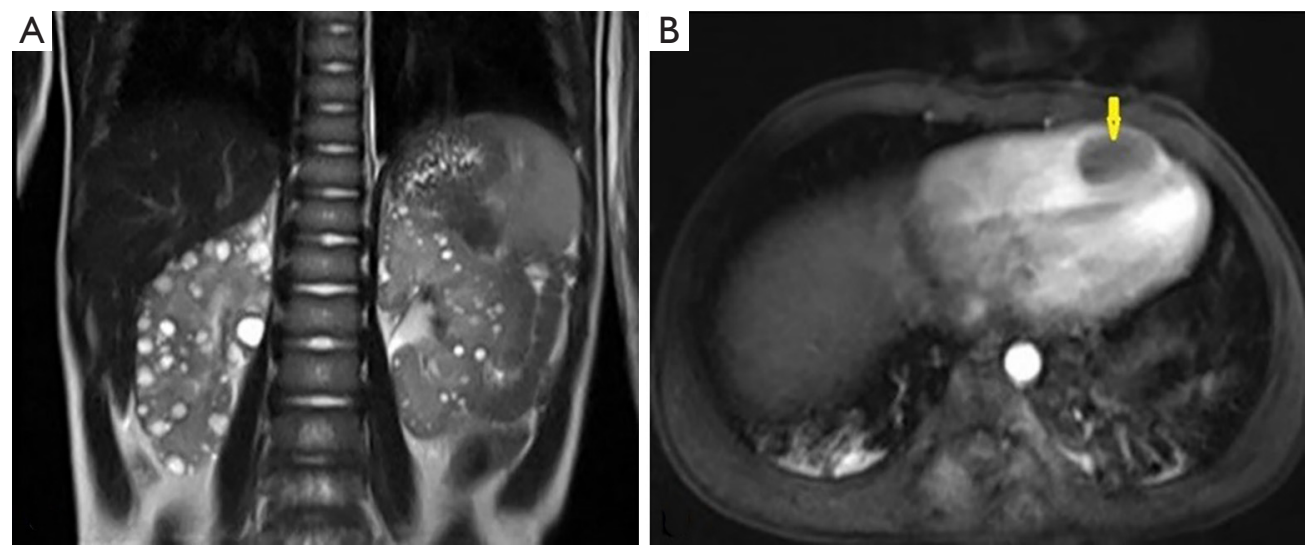

Figure 6 A 2.5-year-old female known tuberous sclerosis complex (Case 2) with multiple renal lesions and mass in the right ventricle of the heart. (A) Coronal T2-weighted images magnetic resonance imaging (MRI) of the abdomen showing multiple high signal intensity bilateral renal lesions (simple cysts). (B) Axial MRI of the abdomen and lower chest showing low signal intensity mass in the right ventricle (arrow).

gestation by normal vaginal delivery. After birth, screening medical imaging was done and T1WIs MRI of the brain showed multiple low signal intensity SENs (Figure 1, feature 7; Figure $5 A$ ), and fluid attenuation inversion recovery (FLAIR) weighted-images MRI of the brain showed multiple high signal intensity SENs (Figure 1, feature 7; Figure 5B). Abdominal T2WIs MRI showed multiple high signal intensity bilateral renal lesions (simple cysts; Figure 1; feature 5+; Figure 6A), and lower chest MRI showed low signal intensity mass in the right ventricle (Figure 1, feature 9; Figure 6B). The patient began having seizures at
3 months old when she started phenobarbital treatment. At the age of 1 year, she continued to have seizures, and the phenobarbital dose was increased. At 2 years of age, seizure frequency increased to 5-12 per day, and she was started on Levetiracetam. At 2.5 years of age, seizures had not improved, so she was started on Topiramate. The patient began having cyanosis and crying during her seizures. After being seen at an emergency department, Topiramate was discontinued and the phenobarbital dose was increased.

In terms of development, she started walking at 15 months old, and she is able to speak a few words. She currently has 
5-12 seizures per day, each one lasting 10-30 seconds. She has multiple seizure types. Because of the worsening seizures, this episode was the "last straw" for her mother, who brought her in for evaluation. Based on these clinical features and radiology findings, the patient was diagnosed with TSC with developmental delay and epilepsy under treatment.

\section{Discussion}

In this article, we reported two cases of TSC and we reviewed the reported similar cases in the last 4.5 years in journals indexed in the PubMed. A total of 65 published case reports met the selection criteria and were included in the literature review. Demography of patients, major and minor features, and genotype results from these cases are shown in Table 1.

\section{Demography}

Herein, we reported two cases of TSC, one in adult man but was diagnosed during infancy and other diagnosed in an infant female. In the literature, out of 65 TSC cases, 37 were female patients and 28 were males. Umeoka et al. (1) reported that TSC can affect males and females in all ethnic groups. Similar to this, Kingswood et al. (70) and Kothare et al. (71) separately reported a slight female predominance $(51-52 \%)$. In the literature, we found that 33 of patients were diagnosed in childhood and 12 cases had clinical features since childhood even though diagnoses were not made until patients were older than 18 years. Staley reported that the mean age of TSC diagnosis was 7.5 years old, ranging from birth to 73 years old (72). Similarly, Zamora et al. (73) reported that features of TSC are mostly detected in fetuses, infants, children or adolescents.

\section{Clinical features}

In this report, we documented two cases of TSC presented with seizures since infancy. In the literature, seizures were reported in 30 patients. Kothare et al. reported that $63 \%$ of TSC patients had experienced at least one seizure attack (71). The most common reported presenting symptoms of TSC were seizures, history of seizures, or infantile spasm (72). Similarly, in other studies, focal or generalized seizures were found to be the most common symptoms (72-75.3\%) $(74,75)$. This is supported by another study that found a similar percentage of patients had a type of epilepsy where more than $50 \%$ of seizures were drug-resistant for a period of time (76). Wang et al. (77) found that seizures occurred in up to $90 \%$ of patients with TSC, and the majority (63\%) of seizures occurred in the first year of life and could be difficult to control.

In the literature, abdominal (mainly renal) symptoms were the second most common reported symptoms. Similarly, Dixon et al. (78) reported renal clinical manifestation in $14(21.53 \%)$ patients, and this was the second most common clinical feature of TSC.

\section{Brain features}

This report and literature review demonstrates that cortical tubers, SENs (Figures 2,3), and SEGA (Figure 4) brain lesions were the most commonly reported major features; they were reported in 53 cases. Umeoka et al. (1) reported that the prevalence of cortical tubers (Figure 1; feature 6) and/or SENs (Figure 1; feature 7) ranges from 95\% to $100 \%$ in TSC patients, indicating that this feature can be an adequate clue for of TSC diagnosis on the basis of brain imaging. Northrup et al. (4) and von Ranke et al. (5) reported that cortical dysplasia and cortical tubers were present in $90 \%$ and $95 \%$ of TSC patients, respectively. In addition, $80-90 \%$ of TSC patients were reported to have cortical tubers and SENs (79).

Regarding brain lesions, cortical tubers are developmental abnormalities characterised by loss of the normal sixlayer structure of the cerebral cortex and the presence of dysmorphic neurons and large astrocytes. They are the cause of neurological symptoms in TSC patients and are best detected by MRI. Cortical tubers are different from cortical dysplasia which is a congenital abnormality that occurs during development when a group of neurons fail to migrate to the proper site in the brain. SENs are benign hamartomas that are commonly calcified and are best diagnosed by CT. SEGAs consist of proliferative astrocytes and giant cells typically located in the foramen of Monro and cause obstructive hydrocephalus with no or partial calcification, gadolinium enhancement and more than $1 \mathrm{~cm}$ in size $(1,4)$. Our patients did in fact have multiple brain lesions.

\section{Skin features}

In the literature, skin features were the second most common major features reported in this review. Skin features were present in 42 patients. This result is very close to the findings of Almobarak et al. (80) who found skin lesions in $64.7 \%$ of patients at the time of presentation. The result 
Table 1 A review of the literature was performed with a PubMed search of the term "tuberous sclerosis complex case reports"

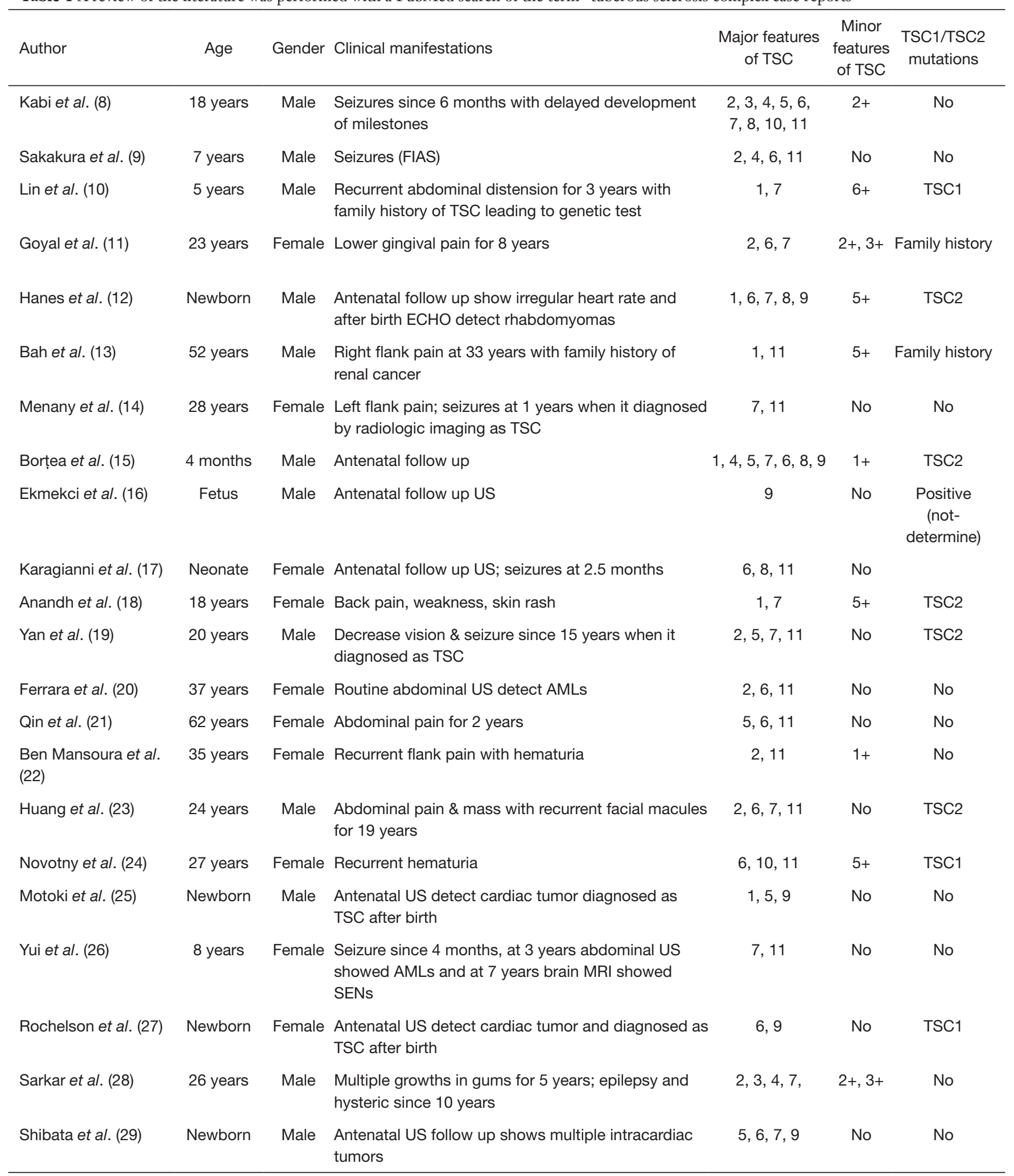

Table 1 (continued) 
Table 1 (continued)

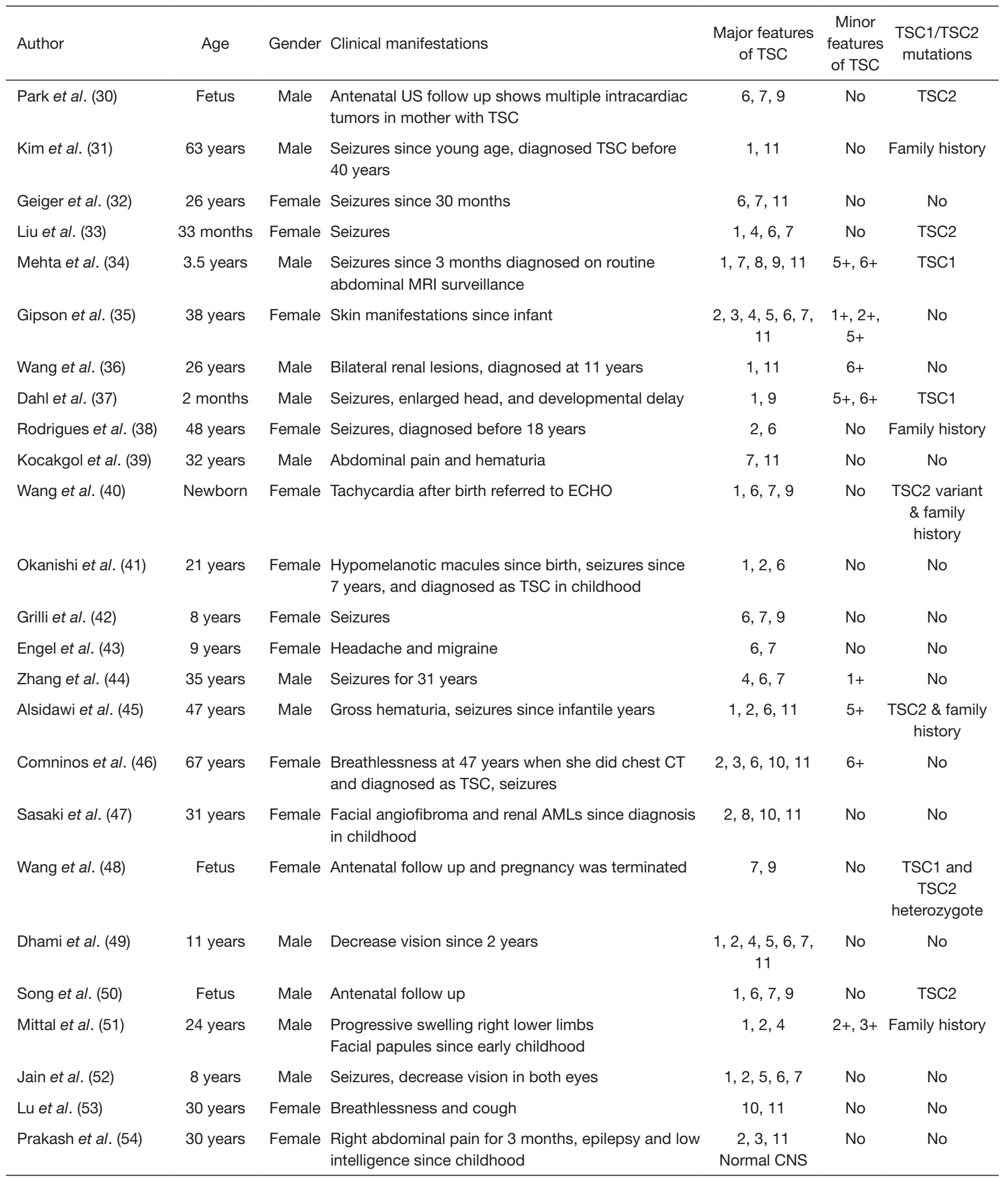

Table 1 (continued) 
Table 1 (continued)

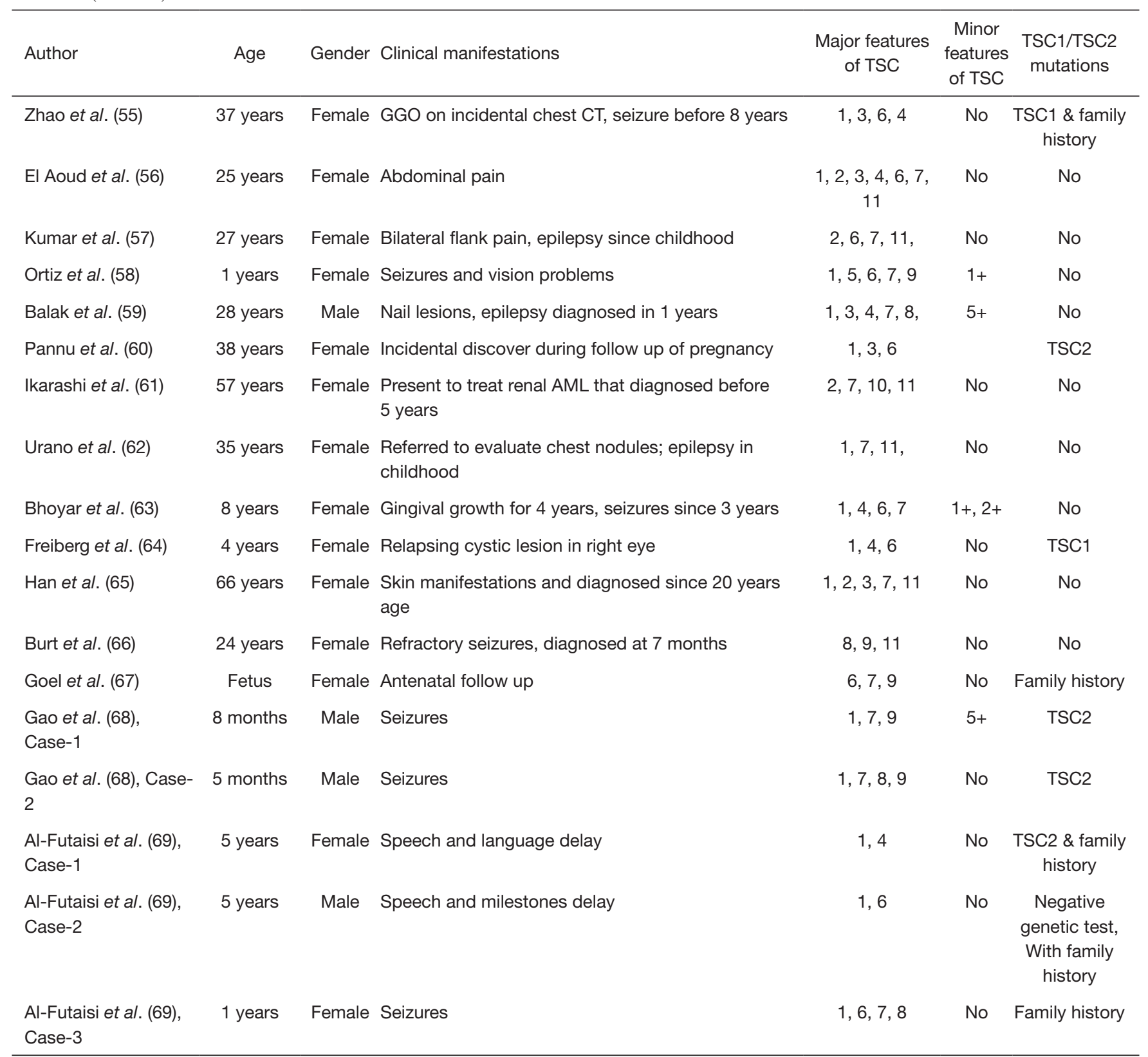

1: Hypomelanotic macules, 2: Angiofibromas, 3: Ungual fibromas, 4: Shagreen patch, 5: Multiple retinal hamartomas, 6: Cortical dysplasias, 7: subependymal nodules, 8: Subependymal giant cell astrocytoma, 9: Cardiac rhabdomyoma, 10: Lymphangioleiomyomatosis, 11: Angiomyolipomas, 1+: Confetti skin lesions, 2+: Dental enamel pits, 3+: Intraoral fibromas, 4+: Retinal achromic patch, 5+: Multiple renal cysts, 6+: Nonrenal hamartomas. TSC, Tuberous sclerosis complex; y, year; m, month; o, old; FIAS, Focal impaired awareness seizures; ECHO, Echocardiography; AML, Angiomyolipoma; SENS, subependymal nodules; SEGA, subependymal giant cell astrocytoma; GGO, ground glass opacity; No, either normal or not available.

is also in line with Rosset et al. (81) who reported that skin manifestations occurred in $70 \%$ of TSC patients. Case-1 of our patients did in fact have multiple skin manifestations.

\section{Renal features}

In our report, renal features were found in both cases. In the literature, renal features were the third most common major 
feature reported. We found them in 33 of TSC cases. The majority were renal AMLs (Figure 1, feature 11; Figure 4) which were reported in 29 cases. Kingswood et al. (70) and Uysal et al. (79) reported that AMLs are the most common renal lesion in TSC and they are often bilateral, multiple, and asymptomatic. Von Ranke et al. found AMLs in 70$80 \%$ of patients with TSC, and they report that the most serious complication is rupture and haemorrhage frequently associated with aneurysm (5). AML is a type of benign tumour that consists of variable numbers of vascular cells, smooth-muscle cells, epithelioid cells, and fat cells $(1,79)$. The second most common renal lesion in patients with TSC is renal cysts (Figure 1; minor feature 5+), which can be single or multiple (1). In the literature, renal cysts were the second most common renal manifestation of TSC; renal cysts were reported in 10 patients. Rarely, TSC is associated with a severe early onset polycystic kidney phenotype due to a large deletion mutation spanning parts of both TSC2 and PKD1 genes on chromosome 16p13 (78). The combination of AMLs and cysts is highly indicative of TSC (79). Our patient did in fact have multiple renal lesions.

\section{Chest features}

Cardiac rhabdomyomas, are benign muscular tumours of the heart. They are commonly located in the ventricular septum, with no clinical features at birth, and commonly regress or even disappear (1). In the literature, cardiac rhabdomyomas (Figure 1; feature 9) was reported in 17 cases, and LAM (Figure 1; feature 10) was reported in 5 cases. Northrup et al. reported that the presence of prenatal cardiac rhabdomyomas were associated with an $80 \%$ risk of TSC (4). LAM was found in 4 cases in the literature. It has been reported that pulmonary manifestations including LAM or "multifocal micro nodular pneumocyte hyperplasia" (MMPH) occur in $1-2.3 \%$ of TSC patients, but higher rates have been documented with the new radiological imaging modalities (1).

\section{Ocular features}

The literature review reveals that ocular features are among the uncommonly reported features. Retinal astrocytic hamartomas (RAHs), (Figure 1; feature 5) were reported in 9 out of 65 cases. Northrup et al. and Uysal et al. reported that retinal hamartomas are a major feature that were observed in up to $50 \%$ of TSC patients, and they also reported that retinal achromic patch is another manifestation $(4,79)$. RAHs are a potential cause of visual deficits in TSC patients (82).

\section{Genotype}

In the literature, genetic tests were available for 23 cases. Within these cases, a TSC1 mutation was reported in 7 cases, a TSC 2 mutation was reported in 14 cases, a mutation in both genes was reported in 1 case, and no mutation was reported in 1 case. Similar to this, de Vries et al. (2) study reported that $64.4 \%$ of TSC patients had a TSC2 mutation, $19.1 \%$ had a TSC1 mutation, and $14.4 \%$ had no mutation. Similarly, Almobarak et al. reported that $65.9 \%$ of patients had a TSC2 mutation, $29.5 \%$ had a TSC1 mutation, and $4.5 \%$ had no mutations (80). He et al. also reported that more patients had a TSC2 mutation compared with TSC1 (71.79\% vs. $28.2 \%$ ) and $10.25 \%$ had no mutations (83). Von Ranke et al. (5) and Nellist et al. (84) considered that identification of a mutation in TSC1 or TSC2 is sufficient for diagnosis of TSC.

\section{Diagnostic clues and medical imaging}

Medical imaging plays an essential role in detecting features of TSC and, thus for diagnosing patients with the disease. However, clinical features should be available for suspicion and investigation of TSC patients.

In the literature, neurological manifestations were the main clues that led to investigation and diagnosis of TSC in 22 patients. Neurological features included seizures in 18 cases, developmental delay in 2 cases, weakness in 1 case, and headache in 1 case. The second most common indication to investigate for TSC was abdominal manifestations which were found in 16 cases, including renal clinical manifestations, such as flank pain and hematuria, in 11 cases, and other abdominal clinical manifestations in 5 cases. Antenatal follow-up by ultrasonography was the feature that led to TSC diagnosis in 11 out of 65 cases. The main clue features that initiated investigation of disease were skin manifestations, chest manifestations, ocular manifestations, gingival and teeth manifestations, and tachycardia after birth in 4, 3, 2, 2, and 1 cases, respectively. The remained 4 cases were incidentally diagnosed, 2 cases during abdominal imaging, 1 case during chest imaging, and 1 case during follow-up pregnancy imaging.

Kija et al. (74) found that skin manifestations led to diagnosis in $33 \%$ of TSC patients. However, in the literature, skin manifestations were the diagnostic clue in only 4 cases. This gap can be explained by that skin lesions were omitted by the patients because they were not causing of alarming manifestations. 
Regarding imaging modalities, Umeoka et al. and von Ranke et al. reported that CT is an effective modality for detection of SENs, because they are commonly associated with calcification. CT can detect cortical tubers, but MRI was found to be more effective than CT in detecting cortical tubers and SEGAs. CT can diagnose AMLs by measuring intratumoral fat density (density $<-20 \mathrm{HU}$ ) with homogenous enhancement after administration of intravenous contrast media. Chest manifestations including LAM and MMPH can also be diagnosed easily by chest CT $(1,5)$.

Echocardiography is the primary diagnostic tool used to investigate cardiac rhabdomyomas. However, MRI or CT can provide further information regarding tumour size and extension (5). Cardiac rhabdomyomas can be detected during antenatal ultrasonography at or after the $22^{\text {nd }}$ week of gestation (79). Gu et al. (85) reported that identification of cardiac tumours by antenatal ultrasonography is often the first feature of TSC, and Davis et al. (86) reported that 35\% of infants with TSC presented with cardiac rhabdomyomas during the antenatal period, as observed by medical imaging.

\section{Pathophysiology of TSC lesions}

Mechanistic target of rapamycin (mTOR) is a serine/ threonine protein kinase that controls eukaryotic cell growth and metabolism. Loss of function mutations in TSC1 or TSC2 lead to hyperactive mTOR which causes abnormal cell proliferation and increases in cell size; this causes formation of brain lesions that occur in TSC patients. Somatic mutations that activate the mTOR complex-1 pathway cause a plethora of neurological diseases $(87,88)$. Brain lesions in TSC are formed during the embryonic period as a consequence of increased activation of mTOR and these lesions can be detected by fetal ultrasonography or brain MRI (89).

Regarding the occurrence of AMLs, Niida et al. (90) reported that loss of heterozygosity of the remaining wild type TSC1 or TSC2 allele was detected in some patients, whereas in other patients, additional yet uncovered mechanisms may be pathogenic.

TSC1 encodes the protein hamartin and TSC 2 gene encodes the protein tuberin. These two proteins act as tumor suppressors by forming the TSC1-TSC2 heterodimer which activates the GTPase-activating protein complex resulting in inhibition of the mTOR. In TSC patients, mutations of TSC1 and TSC2 activate mTOR, leading to abnormal cell proliferation and differentiation and multiple hamartomatous growths in the brain, heart, kidneys, eyes and skin (91).

Oral mTOR inhibitors are effective in treatment of TSC manifestations, for example, Cardis and DeKlotz reported that rapamycin and its analogues inhibit mTOR and impede its overactivation, preventing tumor growth in TSC. Oral mTOR inhibitors are effective in treatment of TSC manifestations. Oral rapamycin is approved by the American Food and Drug administration and by the European Medicines Agency for treatment of pulmonary LAM in TSC. Additionally, topical mTOR inhibitors are effective in treatment of angiofibromas as indicated by consensus guidelines (92).

\section{Conclusions}

TSC can affect males and females in any age and ethnic group. Medical imaging plays an essential role in detecting features and diagnosing TSC. However, clinical features are the main factor that leads to suspected TSC cases and investigation of disease in patients. We reported two cases of TSC. Case 1 presented with seizures from 6 months of age and was diagnosed by multiple calcified subependymal nodules, and Case 2 presented with seizures from 3 months of age and was diagnosed prenatally by a tumour in the heart. In the literature, neurological manifestations, including seizures, were the most common clues that led to investigation and diagnosis of TSC. Abdominal manifestations, including renal manifestations, were the second most common clues for diagnosis, and antenatal follow-up by ultrasonography was the third most common clue for diagnosis. Skin, chest, ocular and gingival manifestations were less-common clues. Tachycardia following birth was the least common clue that led to TSC diagnosis. TSC may be incidentally discovered by medical imaging for any purpose.

\section{Acknowledgments}

The authors would like to thank scribendi.com for their effort in English language editing.

Funding: None.

\section{Footnote}

Conflicts of Interest: All authors have completed the ICMJE uniform disclosure form (available at https://dx.doi. org/10.21037/qims-21-412). The authors have no conflicts of interest to declare. 
Ethical Statement: The authors are accountable for all aspects of the work in ensuring that questions related to the accuracy or integrity of any part of the work are appropriately investigated and resolved. All procedures performed in studies involving human participants were in accordance with the ethical standards of the institutional and/or national research committee(s) and with the Helsinki Declaration (as revised in 2013). Written informed consent was obtained from the patient or legal guardian.

Open Access Statement: This is an Open Access article distributed in accordance with the Creative Commons Attribution-NonCommercial-NoDerivs 4.0 International License (CC BY-NC-ND 4.0), which permits the noncommercial replication and distribution of the article with the strict proviso that no changes or edits are made and the original work is properly cited (including links to both the formal publication through the relevant DOI and the license). See: https://creativecommons.org/licenses/by-nc-nd/4.0/.

\section{References}

1. Umeoka S, Koyama T, Miki Y, Akai M, Tsutsui K, Togashi $\mathrm{K}$. Pictorial review of tuberous sclerosis in various organs. Radiographics 2008;28:e32.

2. de Vries PJ, Belousova E, Benedik MP, Carter T, Cottin V, Curatolo P, et al. TSC-associated neuropsychiatric disorders (TAND): findings from the TOSCA natural history study. Orphanet J Rare Dis 2018;13:157.

3. Byers HM, Jensen DM, Glass IA, Bennett JT. Minimal mosaicism, maximal phenotype: Discordance between clinical and molecular findings in two patients with tuberous sclerosis. Am J Med Genet C Semin Med Genet 2018;178:374-8.

4. Northrup H, Krueger DA; International Tuberous Sclerosis Complex Consensus Group. Tuberous sclerosis complex diagnostic criteria update: recommendations of the 2012 Iinternational Tuberous Sclerosis Complex Consensus Conference. Pediatr Neurol 2013;49:243-54.

5. von Ranke FM, Faria IM, Zanetti G, Hochhegger B, Souza AS Jr, Marchiori E. Imaging of tuberous sclerosis complex: a pictorial review. Radiol Bras 2017;50:48-54.

6. Manoukian SB, Kowal DJ. Comprehensive imaging manifestations of tuberous sclerosis. AJR Am J Roentgenol 2015;204:933-43.

7. Krueger DA, Northrup H; International Tuberous Sclerosis Complex Consensus Group. Tuberous sclerosis complex surveillance and management: recommendations of the 2012 International Tuberous Sclerosis Complex Consensus Conference. Pediatr Neurol 2013;49:255-65.

8. Kabi A, Panda S, Sama S, Kumar S, Kaeley N, Sogal P S. A rare pulmonary lymphangioleiomyomatosis disease in a male with tuberous sclerosis complex. Respir Med Case Rep 2020;31:101150.

9. Sakakura K, Fujimoto A, Ichikawa N, Baba S, Enoki H, Okanishi T. Removal of a temporal lobe cavernous angioma to control epileptic seizures in a patient with tuberous sclerosis complex. Heliyon 2020;6:e04229.

10. Lin WH, Zhang ZH, Wang HL, Ren L, Geng LL. Tuberous sclerosis complex presenting as primary intestinal lymphangiectasia: A case report. World J Clin Cases 2020;8:1995-2000.

11. Goyal L, Agarwal P, Reddy GS, Jain K. Diagnosis and treatment considerations of atypical oral pain in tuberous sclerosis. J Family Med Prim Care 2020;9:2121-4.

12. Hanes I, Muir K, Abdeen N, Sell E. Tuberous sclerosis complex associated intracranial lesion found by antenatal ultrasound. Radiol Case Rep 2020;15:816-8.

13. Bah I, Fahiminiya S, Bégin LR, Hamel N, D'Agostino MD, Tanguay S, Foulkes WD. Atypical tuberous sclerosis complex presenting as familial renal cell carcinoma with leiomyomatous stroma. J Pathol Clin Res 2018;4:167-74.

14. Menany M, Khnaba S, Radouane B, Jidal M, Amil T, Saouab R. Giant bilateral angiomyolipomas with spontaneous hemorrhage and inferior vena cava thrombosis in a patient with tuberous sclerosis. Pan Afr Med J 2017;27:223.

15. Borțea CI, David VL, Stoica F, Mureșan C, Boia M. The Value of Imagistics in Early Diagnosis of Tuberous Sclerosis. Case Rep Pediatr 2020;2020:1309184.

16. Ekmekci E, Ozkan BO, Yildiz MS, Kocakaya B. Prenatal diagnosis of fetal cardiac rhabdomyoma associated with tuberous sclerosis: A case report. Case Rep Womens Health 2018;19:e00070.

17. Karagianni A, Karydakis P, Giakoumettis D, Nikas I, Sfakianos G, Themistocleous M. Fetal subependymal giant cell astrocytoma: A case report and review of the literature. Surg Neurol Int 2020;11:26.

18. Anandh U, Chandrasekar G, Agarwal V. Mammalian target of rapamycin inhibitors in a patient with polycystic kidney disease-1-tuberous sclerosis-2 contiguous gene syndrome. Saudi J Kidney Dis Transpl 2018;29:1475-9.

19. Yan S, Chen Y, Chen R, Tian B, Li Z. Subthreshold micropulse laser photocoagulation therapy in a case of bilateral retinal astrocytic hamartomas with tuberous sclerosis complex: A case report. Medicine (Baltimore) 
2018;97:e13265.

20. Ferrara D, Vallone G, Tedeschi E, Ponsiglione A, Stanzione A, Pisani A, Imbriaco M. An unusual case of tuberous sclerosis incidentally discovered in adulthood: case report and review of the literature. Acta Radiol Open 2018;7:2058460118806328.

21. Qin X, Tao Y, Zhang Z. Retinal astrocytic hamartoma in tuberous sclerosis complex in an elderly person: a case report. BMC Ophthalmol 2018;18:319.

22. Ben Mansoura W, Ben Rhouma S, Jrad M, Zehani A, Boukriba S, Mizouni H. Spontaneous rupture of large bilateral renal angiomyolipomas in a patient with tuberous sclerosis complex: A case report and literature review. Urol Case Rep 2020;30:101124.

23. Huang YJ, Jiang ZP, Chen YP, Wu JQ, Huang JL, Chen YQ, Liang MJ. Malignancy of renal angiomyolipoma from tuberous sclerosis complex with TSC2 mutation. Chin Med J (Engl) 2019;132:103-5.

24. Novotny R, Chlupac J, Marada T, BloudickovaRajnochova S, Vavrinova H, Janousek L, Fronek J. Deceased Donor Renal Transplantation Combined with Bilateral Nephrectomy in a Patient with Tuberous Sclerosis and Renal Failure. Case Rep Transplant 2019;2019:2172163.

25. Motoki N, Inaba Y, Matsuzaki S, Akazawa Y, Nishimura T, Fukuyama T, Koike K. Successful treatment of arrhythmia-induced cardiomyopathy in an infant with tuberous sclerosis complex. BMC Pediatr 2016;16:16.

26. Yui K, Imataka G, Sasaki H, Kawasaki Y, Okanshi T, Shiroki R, Yoshihara S. Improvement in Impaired Social Cognition but Not Seizures by Everolimus in a Child with Tuberous Sclerosis-Associated Autism through Increased Serum Antioxidant Proteins and Oxidant/Antioxidant Status. Case Rep Pediatr 2019;2019:2070619.

27. Rochelson E, Sharma M, Clark BC. Massive ST-segment elevations in a newborn with tuberous sclerosis and ventricular rhabdomyomas. HeartRhythm Case Rep 2020;6:60-2.

28. Sarkar S, Khaitan T, Sinha R, Kabiraj A. Tuberous sclerosis complex: A case report. Contemp Clin Dent 2016;7:236-9.

29. Shibata Y, Maruyama H, Hayashi T, Ono H, Wada Y, Fujinaga H, Fujino S, Nagasawa J, Amari S, Tsukamoto K, Ito Y. Effect and Complications of Everolimus Use for Giant Cardiac Rhabdomyomas with Neonatal Tuberous Sclerosis. AJP Rep 2019;9:e213-7.

30. Park H, Chang CS, Choi SJ, Oh SY, Roh CR. Sirolimus therapy for fetal cardiac rhabdomyoma in a pregnant woman with tuberous sclerosis. Obstet Gynecol Sci
2019;62:280-4.

31. Kim K, Kim S, Na KY, Chae DW, Chin HJ. Severe Hypocalcemia in a Patient with Tuberous Sclerosis Complex. Electrolyte Blood Press 2019;17:21-4.

32. Geiger MA, Cantador AA, Guillaumon AT. Thoracic aortic aneurysm in a patient with tuberous sclerosis. J Vasc Bras 2019;18:e20160017.

33. Liu X, Zhang Y, Hao Y, Chen Y, Chen C. Tuberous sclerosis complex presenting as convulsive status epilepticus followed by hypoxic cerebropathy: A case report. Medicine (Baltimore) 2019;98:e15545.

34. Mehta S, Rusyn L, Ginsburg H, Hajdu C, Kohn B. Pancreatic Neuroendocrine Tumor in a Young Child With Tuberous Sclerosis Complex 1. J Endocr Soc 2019;3:1201-6.

35. Gipson TT. Consequences of delay in screening, monitoring, and treatment of angiomyolipoma and tuberous sclerosis: A case report . Clin Nephrol 2018;90:71-5.

36. Wang CN, Wang SY, Lin MJ, Wang HW. Occult Renal Cell Carcinoma of Eosinophilic Morphology Detected within Renal Angiomyolipoma Mass in a Patient with Tuberous Sclerosis Complex. Chin Med J (Engl) 2017;130:1505-6.

37. Dahl NA, Luebbert T, Loi M, Neuberger I, Handler MH, Kleinschmidt-DeMasters BK, Mulcahy Levy JM. Chordoma Occurs in Young Children With Tuberous Sclerosis. J Neuropathol Exp Neurol 2017;76:418-23.

38. Rodrigues M, Padrão E, Irion K. Multifocal micronodular pneumocyte hyperplasia associated with tuberous sclerosis complex: A case report without lymphangioleiomyomatosis association. Rev Port Pneumol (2006) 2017;23:239-40.

39. Kocakgol DO, Cayli E, Oguz S, Dinc H. Selective Arterial Embolization of Giant Renal Angiomyolipoma Associated with Tuberous Sclerosis Complex Using Particular and Liquid Embolic Agents. Eurasian J Med 2018;50:130-3.

40. Wang F, Xiong S, Wu L, Chopra M, Hu X, Wu B. A novel TSC2 missense variant associated with a variable phenotype of tuberous sclerosis complex: case report of a Chinese family. BMC Med Genet 2018;19:90.

41. Okanishi T, Fujimoto A, Nishimura M, Niimi K, Kanai S, Enoki H. Resective Surgery for Double Epileptic Foci Overlapping Anterior and Posterior Language Areas: A Case of Epilepsy With Tuberous Sclerosis Complex. Front Neurol 2018;9:343.

42. Grilli G, Moffa AP, Perfetto F, Specchiulli LP, Vinci R, Macarini L, Zizzo L. Neuroimaging Features of Tuberous Sclerosis Complex and Chiari Type I Malformation: A 
Rare Association. J Pediatr Neurosci 2018;13:224-8.

43. Engel SGK, Bhatia S. Tip of the Iceberg: Forme Fruste Tuberous Sclerosis in a Child. J Pediatr Neurosci 2018;13:195-7.

44. Zhang L, Jiang XY, Chen N, Hao NY, Zhou D, Li JM. Progressive cystic lesion in a middle-aged patient with tuberous sclerosis complex: A case report. Medicine (Baltimore) 2018;97:e0407.

45. Alsidawi S, Kasi PM. Exceptional response to everolimus in a novel tuberous sclerosis complex-2 mutationassociated metastatic renal-cell carcinoma. Cold Spring Harb Mol Case Stud 2018;4:a002220.

46. Comninos AN, Yang L, Abbara A, Dhillo WS, Bassett JHD, Todd JF. Frequent falls and confusion: recurrent hypoglycemia in a patient with tuberous sclerosis complex. Clin Case Rep 2018;6:904-9.

47. Sasaki H, Iwami D, Hotta K, Morita K, Naka T, Shinohara N. Spontaneous reduction of native kidney size involving angiomyolipoma lesions in a kidney transplant recipient with tuberous sclerosis complex. Int J Urol 2018;25:513-4.

48. Wang CC, Wang CY, Lai YJ, Chang TY, Su HY. Prenatal diagnosis of tuberous sclerosis complex using fetal ultrasonography and magnetic resonance imaging and genetic testing. Taiwan J Obstet Gynecol 2018;57:163-5.

49. Dhami A, Devi PV, Bhende M. Tuberous sclerosis complex with Best's vitelliform macular dystrophy: A combined presentation. Indian J Ophthalmol 2018;66:295-6.

50. Song ES, Jeong K, Kim G, Hwang IJ, Lee MJ, Cho HJ, Cho YK. Spontaneous Regression of Cardiac Rhabdomyoma Presenting as Severe Left Ventricular Inlet Obstruction in a Neonate with Tuberous Sclerosis. Case Rep Cardiol 2018;2018:8395260.

51. Mittal A, Vinay K, De D, Handa S, Sinha A. Tuberous Sclerosis Complex and Diffuse Lipomatosis: Case Report of a Rare Association. Indian Dermatol Online J 2018;9:37-9.

52. Jain KA, Jain AB. Chronic papilledema in a child with classical tuberous sclerosis. Indian J Ophthalmol 2018;66:127-8.

53. Lu HS, Cao XQ, Chen WF. Pulmonary Lymphangiomyomatosis Associated with Renal and Hepatic Angiomyolipoma Mass in a Patient with Tuberous Sclerosis Complex. Chin Med J (Engl) 2017;130:3017-8.

54. Prakash G, Sankhwar S, Jhanwar A, Singh K. Bilateral renal angiomyolipoma presenting as tuberous sclerosis syndrome. BMJ Case Rep 2016;2016:bcr2016214778.

55. Zhao TT, Wang YS, Li Y, Ma M, Li AM, Cai HR, Fan XS, Meng FQ, Miao LY. A Tuberous Sclerosis Family with
TSC1 (c.1030-1G>A) Mutation Found through a Female Presenting as Multiple Ground Glass Nodules in Chest Computed Tomography Incidentally. Chin Med J (Engl) 2017;130:2510-2.

56. El Aoud S, Frikha F, Snoussi M, Salah RB, Bahloul Z. Tuberous sclerosis complex (Bourneville-Pringle disease) in a 25-year- old female with bilateral renal angiomyolipoma and secondary hypertension. Saudi J Kidney Dis Transpl 2017;28:633-8.

57. Kumar S, Modi P. Tuberous sclerosis with bilateral giant renal angiomyolipomas. Indian J Med Res 2016;143:667-8.

58. Ortiz Z AI, Cárdenas PL, Escaf LC, Peralta M. Cortical blindness as severe neuro-ophthalmological manifestation of tuberous sclerosis complex. GMS Ophthalmol Cases 2017;7:Doc11.

59. Balak DM, Zonnenberg BA, Spitzer-Naaijkens JM, Hulshof MM. A 28-Year-Old Male Patient with Nail Tumors, Skin Lesions, and Epilepsy. Case Rep Dermatol 2017;9:12-9.

60. Pannu BS, Apala DR, Kotecha A, Boland JM, Iyer VN. Multifocal micronodular pneumocyte hyperplasia (MMPH) in a patient with tuberous sclerosis-evidence for long term stability. Respir Med Case Rep 2017;20:113-5.

61. Ikarashi D, Mue Y, Shiomi E, Takayama M, Kato R, Kato Y, Ishida K, Abe T, Sugai T, Obara W. Efficacy of Everolimus for Treating Renal Angiomyolipoma with Inferior Vena Cava Thrombus Associated with Tuberous Sclerosis: A Case Report. Urol Case Rep 2017;11:11-3.

62. Urano T, Hayama N, Tanaka J, Horio Y, Sato M, Hattori S, Takahashi G, Takahashi F, Takeuchi T, Harada K, Takiguchi H, Tomomatsu H, Tomomatsu K, Takihara T, Niimi K, Oguma T, Aoki T, Ogura G, Nakamura N, Asano K. Progressive Multifocal Micronodular Pneumocyte Hyperplasia in the Lungs of a Patient with Tuberous Sclerosis Complex: A Case Report. Tokai J Exp Clin Med 2016;41:230-2.

63. Bhoyar N, Gupta S, Ghosh S. Odontogenic myxofibroma of gingiva in a pediatric patient with tuberous sclerosis: A rare case report. Contemp Clin Dent 2016;7:558-61.

64. Freiberg FJ, Kunstmann E, König T, Matlach J, Kampik D. Conjunctival lymphangioma in a 4-year-old girl revealed tuberous sclerosis complex. GMS Ophthalmol Cases 2016;6:Doc09.

65. Han XC, Zheng LQ, Zheng TG. Onychogryphosis in tuberous sclerosis complex: an unusual feature. An Bras Dermatol 2016;91:116-8.

66. Burt J, Rop B, Derrick E, Armaly J, Siddiqui U. Myocardial Fatty Foci in Tuberous Sclerosis Complex: 
Imaging Findings. Cureus 2016;8:e693.

67. Goel R, Aggarwal N, Lemmon ME, Bosemani T. Fetal and maternal manifestations of tuberous sclerosis complex: Value of fetal MRI. Neuroradiol J 2016;29:57-60.

68. Gao S, Wang Z, Xie Y. Two novel TSC2 mutations in pediatric patients with tuberous sclerosis complex: Case report. Medicine (Baltimore) 2018;97:e11533.

69. Al-Futaisi A, Idris A, Al-Sayegh A, Al-Mamari WS. Coexistence of Autism Spectrum Disorders Among Three Children with Tuberous Sclerosis Complex: Case reports and review of literature. Sultan Qaboos Univ Med J 2016;16:e520-4.

70. Kingswood JC, Belousova E, Benedik MP, Carter T, Cottin V, Curatolo P, et al. Renal angiomyolipoma in patients with tuberous sclerosis complex: findings from the TuberOus SClerosis registry to increase disease Awareness. Nephrol Dial Transplant 2019;34:502-8.

71. Kothare SV, Singh K, Hochman T, Chalifoux JR, Staley BA, Weiner HL, Menzer K, Devinsky O. Genotype/ phenotype in tuberous sclerosis complex: associations with clinical and radiologic manifestations. Epilepsia 2014;55:1020-4.

72. Staley BA, Vail EA, Thiele EA. Tuberous sclerosis complex: diagnostic challenges, presenting symptoms, and commonly missed signs. Pediatrics 2011;127:e117-25.

73. Zamora EA, Aeddula NR. Tuberous Sclerosis. In: StatPearls. Treasure Island (FL): StatPearls Publishing; May 7, 2020.

74. Kija E, Schlegel B, Samia P, Wessels M, Wilmshurst JM. Tuberous sclerosis complex in the Western Cape, South Africa: The clinical presentation features. S Afr Med J 2017;107:295-8.

75. Lin S, Zeng JB, Zhao GX, Yang ZZ, Huang HP, Lin MT, Wu ZY, Wang N, Chen WJ, Fang L. Tuberous Sclerosis Complex in Chinese patients: Phenotypic analysis and mutational screening of TSC1/TSC2 genes. Seizure 2019;71:322-7.

76. Vignoli A, La Briola F, Turner K, Scornavacca G, Chiesa V, Zambrelli E, Piazzini A, Savini MN, Alfano RM, Canevini MP. Epilepsy in TSC: certain etiology does not mean certain prognosis. Epilepsia 2013;54:2134-42.

77. Wang S, Fallah A. Optimal management of seizures associated with tuberous sclerosis complex: current and emerging options. Neuropsychiatr Dis Treat 2014;10:2021-30.

78. Dixon BP, Hulbert JC, Bissler JJ. Tuberous sclerosis complex renal disease. Nephron Exp Nephrol 2011;118:e15-20.
79. Uysal SP, ahin M. Tuberous sclerosis: a review of the past, present, and future Turk J Med Sci 2020;50:1665-76.

80. Almobarak S, Almuhaizea M, Abukhaled M, Alyamani S, Dabbagh O, Chedrawi A, Khan S, Aldhalaan H. Tuberous Sclerosis Complex: Clinical Spectrum and Epilepsy: A Retrospective Chart Review Study. Transl Neurosci 2018;9:154-60.

81. Rosset C, Netto CBO, Ashton-Prolla P. TSC1 and TSC2 gene mutations and their implications for treatment in Tuberous Sclerosis Complex: a review. Genet Mol Biol 2017;40:69-79.

82. Wan MJ, Chan KL, Jastrzembski BG, Ali A. Neuroophthalmological manifestations of tuberous sclerosis: current perspectives. Eye Brain 2019;11:13-23.

83. He J, Zhou WJ, Shi J, Lin JL, Zhang BQ, Sun ZH. Analysis of genotypes, EEG and phenotypes of tuberous sclerosis complex patients. Zhonghua Yi Xue Za Zhi 2020;100:136-40.

84. Nellist M, Brouwer RW, Kockx CE, van Veghel-Plandsoen M, Withagen-Hermans C, Prins-Bakker L, HoogeveenWesterveld M, Mrsic A, van den Berg MM, Koopmans AE, de Wit MC, Jansen FE, Maat-Kievit AJ, van den Ouweland A, Halley D, de Klein A, van IJcken WF. Targeted Next Generation Sequencing reveals previously unidentified TSC1 and TSC2 mutations. BMC Med Genet 2015;16:10.

85. Gu X, Han L, Chen J, Wang J, Hao X, Zhang Y, Zhang J, Ge S, He Y. Antenatal screening and diagnosis of tuberous sclerosis complex by fetal echocardiography and targeted genomic sequencing. Medicine (Baltimore) 2018;97:e0112.

86. Davis PE, Filip-Dhima R, Sideridis G, Peters JM, Au KS, Northrup H, Bebin EM, Wu JY, Krueger D, Sahin M; Tuberous Sclerosis Complex Autism Center of Excellence Research Network. Presentation and Diagnosis of Tuberous Sclerosis Complex in Infants. Pediatrics 2017;140:e20164040.

87. Saxton RA, Sabatini DM. mTOR Signaling in Growth, Metabolism, and Disease. Cell 2017;168:960-76.

88. Feliciano DM. The Neurodevelopmental Pathogenesis of Tuberous Sclerosis Complex (TSC). Front Neuroanat 2020;14:39.

89. Prabowo AS, Anink JJ, Lammens M, Nellist M, van den Ouweland AM, Adle-Biassette H, Sarnat HB, FloresSarnat L, Crino PB, Aronica E. Fetal brain lesions in tuberous sclerosis complex: TORC1 activation and inflammation. Brain Pathol 2013;23:45-59.

90. Niida Y, Stemmer-Rachamimov AO, Logrip M, Tapon D, Perez R, Kwiatkowski DJ, Sims K, MacCollin M, Louis 
DN, Ramesh V. Survey of somatic mutations in tuberous sclerosis complex (TSC) hamartomas suggests different genetic mechanisms for pathogenesis of TSC lesions. Am J Hum Genet 2001;69:493-503.

91. Sciacca P, Giacchi V, Mattia C, Greco F, Smilari P, Betta $\mathrm{P}$, Distefano G. Rhabdomyomas and tuberous sclerosis

Cite this article as: Alshoabi SA, Hamid AM, Alhazmi FH, Qurashi AA, Abdulaal OM, Aloufi KM, Daqqaq TS. Diagnostic features of tuberous sclerosis complex: case report and literature review. Quant Imaging Med Surg 2022;12(1):846-861. doi: 10.21037/qims-21-412 complex: our experience in 33 cases. BMC Cardiovasc Disord 2014;14:66.

92. Cardis MA, DeKlotz CMC. Cutaneous manifestations of tuberous sclerosis complex and the paediatrician's role. Arch Dis Child 2017;102:858-63. 